\title{
Double differential cross section for light mass fragment production on tens of MeV proton, deuteron, helium and carbon induced reactions
}

\author{
Toshiya Sanami ${ }^{1,2, a}$, Yuji Yamaguchi ${ }^{3}$, Yusuke Uozumi ${ }^{3}$, Masayuki Hagiwara ${ }^{1,2}$, and Yusuke Koba ${ }^{4}$ \\ ${ }^{1}$ High Energy Accelerator Research Organization (KEK), Oho 1-1, Tsukuba, Ibaraki 305-0801, Japan \\ 2 The graduate university for advanced studies (SOKENDAI), Oho 1-1, Tsukuba, Ibaraki 305-0801, Japan \\ 3 Kyushu University, Japan \\ 4 National Institute for Quantum and Radiological Science and technology, Japan
}

\begin{abstract}
Double differential cross sections (DDXs) of light mass fragment (LMFs - Li,Be,B,C,N and O) productions were measured for tens of $\mathrm{MeV}$ proton, deuteron helium and carbon induced reactions on $\mathrm{Be}$, $\mathrm{C}, \mathrm{Al}, \mathrm{Ti}$ and $\mathrm{Cu}$ targets. The incident energies for the measurements were chosen to allow us to compare DDXs with same incident energy but different projectiles on various targets. Systematic data were obtained to see the differences between projectile energies, particles, targets and emitted particles. From the comparison, reaction processes of not only evaporation from complete fusion nucleus, but also scattering, pickup, stripping and projectile fragmentation were observed.
\end{abstract}

\section{Introduction}

Double differential cross sections (DDXs) for light mass fragment production are important parameters to estimate energy deposition within a micro volume through nuclear reactions caused by high-energy particles. The energy deposition after nuclear reaction is not expected since the high-energy particle generally has low energy transfer (LET). In other words, the nuclear reaction generating light mass fragment changes low LET particle to high LET one. The phenomenon induces unexpected or unwanted effects on materials and devices such as single event effects on silicon devices, [1] for example.

The DDXs were calculated using nuclear reaction models in particle transport codes. The nuclear reaction model consists of combination of evaporation and nucleonnucleon processes of target and projectile. To simulate the process, intra-nuclear cascade and evaporation models for nucleon induced reactions, quantum molecular dynamics and evaporation for nucleus are used frequently [2]. In addition to the processes, stripping, pick-up and breakup are known for both nucleon and nucleus induced reactions.

Experimental data of the DDX are required to verify and validate the results calculated with the models $[3,4]$. For proton induced fragment production process, we measured $\mathrm{Li}, \mathrm{Be}, \mathrm{B}$ and $\mathrm{C}$ production DDXs of 40 to $300 \mathrm{MeV}$ protons on $\mathrm{C}, \mathrm{Al}, \mathrm{Ti}$ and $\mathrm{Cu}$ targets using Bragg curve counter [6-9]. For incident ions, however less data and comparisons are available in this energy range. Bhattacharya et al. reports asymmetric binary splitting of the compound nucleus and another mechanism for $\mathrm{Li}$ and $\mathrm{Be}$ at forward angle in his paper for the ${ }^{27} \mathrm{Al}(\mathrm{He}, \mathrm{x})$ reaction at $E_{\text {he }}=60 \mathrm{MeV}$ [10]. Förtsch et al. reports contribution of complete fusion and break-up-fusion to intermediate mass

a e-mail: toshiya.sanami@kek.jp fragment production for the ${ }^{27} \mathrm{Al}\left({ }^{12} \mathrm{C}, \mathrm{x}\right)$ reaction at $\mathrm{E}_{12 C}=$ $156 \mathrm{MeV}$ [11]. Motobayashi et al pointed out $\alpha$-transfer reactions between light nuclei through calculation [12]. These processes should be implemented in the reaction models of particle transport codes properly.

In this study, we provide a set of experimental data for fragment production with combinations of projectile and target nucleus by using the same methodology for proton induced light mass fragment measurement [6-9]. We choose four different incident particles, p, d, He and $\mathrm{C}$, having same energy, $25 \mathrm{MeV}, 50 \mathrm{MeV}, 70 \mathrm{MeV}$ and $140 \mathrm{MeV}$ as incident particles. As targets, we selected Be, $\mathrm{C}, \mathrm{Al}, \mathrm{Ti}$ and $\mathrm{Cu}$ to cover light to medium nuclei. Light mass fragments of $\mathrm{Li}, \mathrm{Be}, \mathrm{B}, \mathrm{C}, \mathrm{N}$ and $\mathrm{O}$ were measured at 30, 60 and 90 degrees.

\section{Experimental}

Details of fragment measurement using Bragg Curve Counters (BCCs) and experimental procedure were described elsewhere [6-9], thus only an outline is presented in this section.

Figure 1 shows the experimental setup. In this setup, three BCCs were mounted on a scattering chamber at 30 , 60 and 90 degrees with respect to the beam direction. The scattering chamber was installed in the beam line of the Cyclotron facility at National Institute of Radiological Sciences (NIRS), Japan.

Table 1 summarizes a list of targets for incident particles and its energies. Beams of $\mathrm{p}, \mathrm{d}, \mathrm{He}$ and $\mathrm{C}$, were chosen with energies of $25 \mathrm{MeV}, 50 \mathrm{MeV}, 70 \mathrm{MeV}$ and $140 \mathrm{MeV}$. Targets of Be, C, Al, Ti and $\mathrm{Cu}$ were chosen. Most of the beams were supplied from the Cyclotron. Only data for $140 \mathrm{MeV}$ proton was taken at Ring cyclotron of Research Center of Nuclear Physics, Osaka university

(C) The Authors, published by EDP Sciences. This is an Open Access article distributed under the terms of the Creative Commons Attribution License 4.0 (http://creativecommons.org/licenses/by/4.0/). 


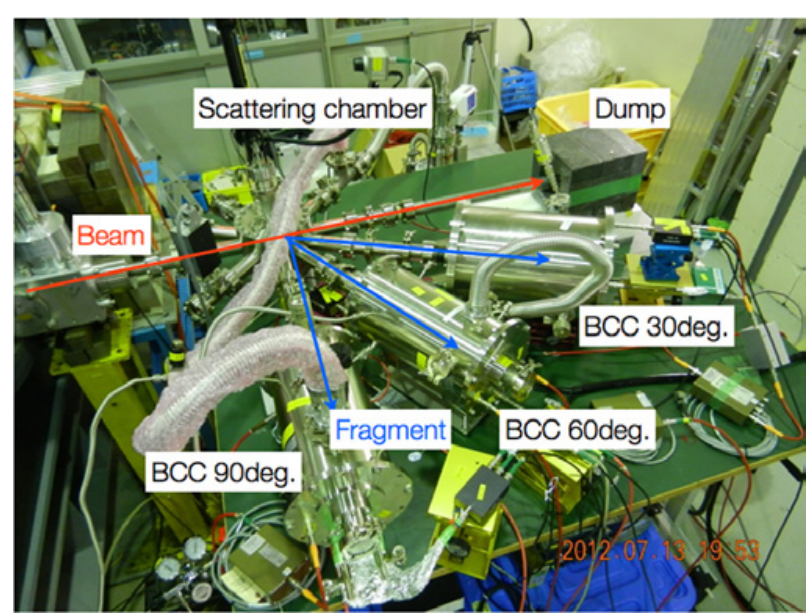

Figure 1. Experimental setup.

Table 1. List of targets for incident particle and their energies. (Note: 72 and $144 \mathrm{MeV}$ employed instead of 70 and $140 \mathrm{MeV}$, respectively, for carbon incident).

\begin{tabular}{|c|c|c|c|c|c|c|c|c|c|c|}
\hline $\begin{array}{c}\text { Energy } \\
{[\text { MeV] }}\end{array}$ & \multicolumn{9}{|c|}{ Proton incident } & \multicolumn{5}{|c|}{ Deuteron incident } \\
\hline 24 & $\mathrm{Be}$ & $\mathrm{C}$ & $\mathrm{Al}$ & $\mathrm{Ti}$ & $\mathrm{Cu}$ & $\mathrm{Be}$ & $\mathrm{C}$ & $\mathrm{Al}$ & & $\mathrm{Cu}$ \\
\hline 50 & $\mathrm{Be}$ & $\mathrm{C}$ & $\mathrm{Al}$ & $\mathrm{Ti}$ & $\mathrm{Cu}$ & $\mathrm{Be}$ & $\mathrm{C}$ & $\mathrm{Al}$ & $\mathrm{Ti}$ & $\mathrm{Cu}$ \\
\hline 70 & & $\mathrm{C}$ & $\mathrm{Al}$ & & & & & & & \\
\hline 140 & & $\mathrm{C}$ & $\mathrm{Al}$ & $\mathrm{Ti}$ & $\mathrm{Cu}$ & & & & & \\
\hline $\begin{array}{c}\text { Energy } \\
{[\mathbf{M e V}]}\end{array}$ & \multicolumn{9}{|c|}{ Helium incident } & \multicolumn{6}{|c|}{ Carbon incident } \\
\hline 24 & & & & & & & & & & \\
\hline 50 & & $\mathrm{C}$ & $\mathrm{Al}$ & & & $\mathrm{Be}$ & $\mathrm{C}$ & $\mathrm{Al}$ & $\mathrm{Ti}$ & $\mathrm{Cu}$ \\
\hline 70 & $\mathrm{Be}$ & $\mathrm{C}$ & $\mathrm{Al}$ & $\mathrm{Ti}$ & $\mathrm{Cu}$ & $\mathrm{Be}$ & $\mathrm{C}$ & $\mathrm{Al}$ & $\mathrm{Ti}$ & $\mathrm{Cu}$ \\
\hline 140 & & & & & & & $\mathrm{C}$ & $\mathrm{Al}$ & & \\
\hline
\end{tabular}

Table 2. Thickness and style of targets.

\begin{tabular}{|l|l|l|}
\hline Target material & Thickness & Style \\
\hline Beryllium & $5 \mu \mathrm{m}$ & Self support \\
\hline Graphite & $206 \mu \mathrm{g} / \mathrm{cm}^{2}$ & Self support \\
\hline Aluminium & $0.8 \mu \mathrm{m}$ & Self support \\
\hline Titanium & $1 \mu \mathrm{m}$ & Self support \\
\hline Copper & $1 \mu \mathrm{m}$ & Self support \\
\hline
\end{tabular}

(RCNP), Japan. Blank points were not measured since limitation of machine time availability.

The thicknesses of the targets are listed on Table 2. The targets were mounted on a ladder of a target changer installed at the center of the chamber.

Beam from the cyclotron was focused at the center of the target. After passing through the target, the beam was lead to the electrically isolated beam dump, located at approximately $1.5 \mathrm{~m}$ downstream, made of graphite block, to measure the number of incident particles. The beam position and size were observed using a $\mathrm{ZnS}$ screen mounted on the target changer ladder in prior to cross section measurement.

On the target, fragments were generated through nuclear reactions with beam particles. The fragments emitted from the target were measured using BCCs connected to the scattering chamber.

Figure 2 shows a schematic drawing of the BCC. The $\mathrm{BCC}$ is a parallel plate ionization chamber with a grid. The

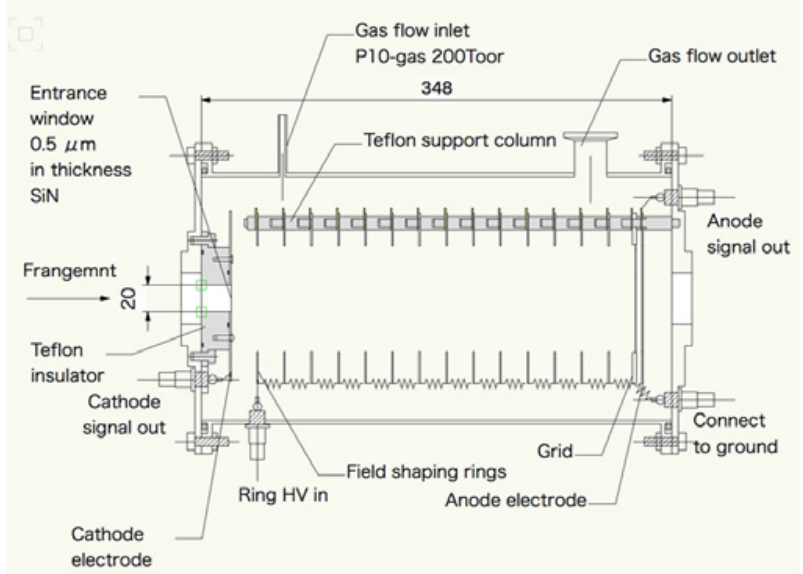

Figure 2. Schematic drawing of a Bragg Curve Counter(BCC).

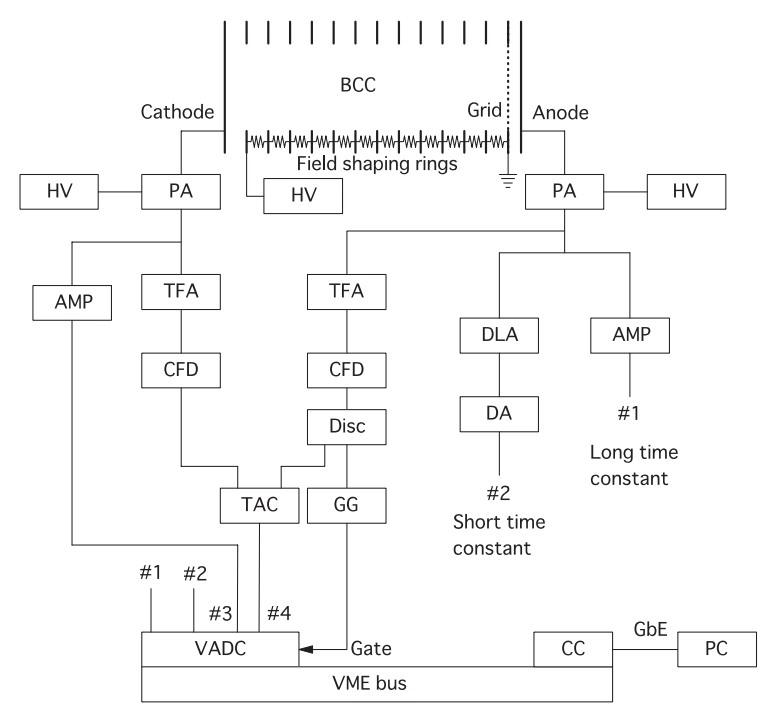

$$
\begin{aligned}
& \text { CFD : Constant Fraction Discriminator } \\
& \text { Disc : Discriminator } \\
& \text { TAC : Time to Amplitude Convertor } \\
& \text { VADC : Voltage ADC } \\
& \text { CC : Crate Controller } \\
& \text { PC : Personal Computer }
\end{aligned}
$$

Figure 3. Block diagram of electronics circuit.

grid is placed in between an anode and cathode electrode, $5 \mathrm{~mm}$ in front of the anode. The distance between the cathode and grid is $30 \mathrm{~cm}$, while 14 field shaping rings having an $8 \mathrm{~cm}$ inner diameter are installed with $2 \mathrm{~cm}$ steps between the cathode and grid to provide uniform electric fields. At the center of the cathode electrode, thin window that consists of a $20 \mathrm{~mm}$ in diameter hole covered with a $\mathrm{SiN}$ membrane, $0.5 \mu \mathrm{m}$ in thickness, with $500 \mu \mathrm{m}$ in thickness support frame is placed to enable a fragment to enter in the BCC. These electrodes are installed in an O-ring sealed stainless steel chamber to be filled with a low pressure counting gas, $\mathrm{Ar}+10 \% \mathrm{CH}_{4}$ with $0.0534 \mathrm{MPa}$ (400 Torr). High voltages were applied to each electrode to induce electric fields the strengths of which are $0.16 \mathrm{~V} / \mathrm{cm} /$ Torr and $0.64 \mathrm{~V} / \mathrm{cm} /$ Torr for cathodegrid and grid-anode, respectively.

The output signals from each BCC were processed using standard NIM and VME modules. The signals 


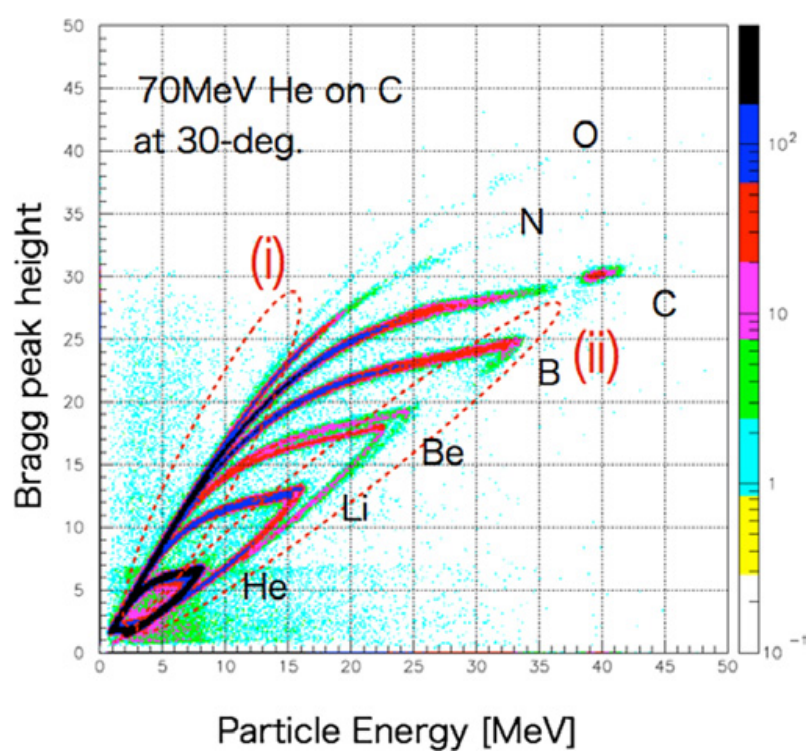

Figure 4. Two dimensional spectrum of particle energy and Bragg peak height for $70 \mathrm{MeV} \mathrm{He}$ on $\mathrm{C}$ target, measured at 30 degrees emission angle.

from the anode electrodes were fed into pre-amplifiers. The preamplifier output connected to each anode was fed into two amplifiers (ORTEC model 460 and 572A) with short $(0.04 \mu \mathrm{s})$ and long $(6 \mu \mathrm{s})$ shaping times to obtain signals related to Bragg peak and energy, respectively. In addition to this, pulse height signals from the cathodes were measured with long time constant amplifiers.

Timing signals were derived using timing filter amplifiers and constant fraction discriminators for anodes and cathodes. Time difference between anode and cathode timing signals was measured using Time-to-amplitude convertor (TAC Canberra model 2145) module. The pulse height signals from amplifiers and TAC were fed into VME analog-to-digital convertors (VADC: A3400 Nikiglass Co., LTD.). The ADC data were accumulated using VME crate controller (SVP511 Nikiglass Co., LTD.), and Linux PC connected with Gigabit Ethernet.

Figure 4 shows typical measured data taken by BCC at angle of 30 degrees, with Bragg peak vs Energy two dimensional plot style for the case of $70 \mathrm{MeV}$ helium impinging on graphite target. As shown in this figure, very clear separation was derived for He to $\mathrm{O}$ fragments.

In addition, the low energy events shown in Fig. 4 as (i), which were too low energy to form Bragg peak, were also separated using range-energy plot that can be derived from time-difference between signals from cathode and anode, and ratio between cathode and anode pulse heights [6]. By using this separation, minimum energy of separation reaches down to $0.5 \mathrm{MeV} / \mathrm{u}$.

On the other hand, the events shown in Fig. 4 as (ii), which were too high energy to stop within BCC length, were used as data points with compensating missing energy based on energy loss calculation with counting gas type and pressure [7].

It should be stressed that these two techniques are essential to cover required energy range for fragment measurement in several tens of $\mathrm{MeV}$ energy region.

After particle identification, pulse height channel spectra were obtained for each fragments. The spectra

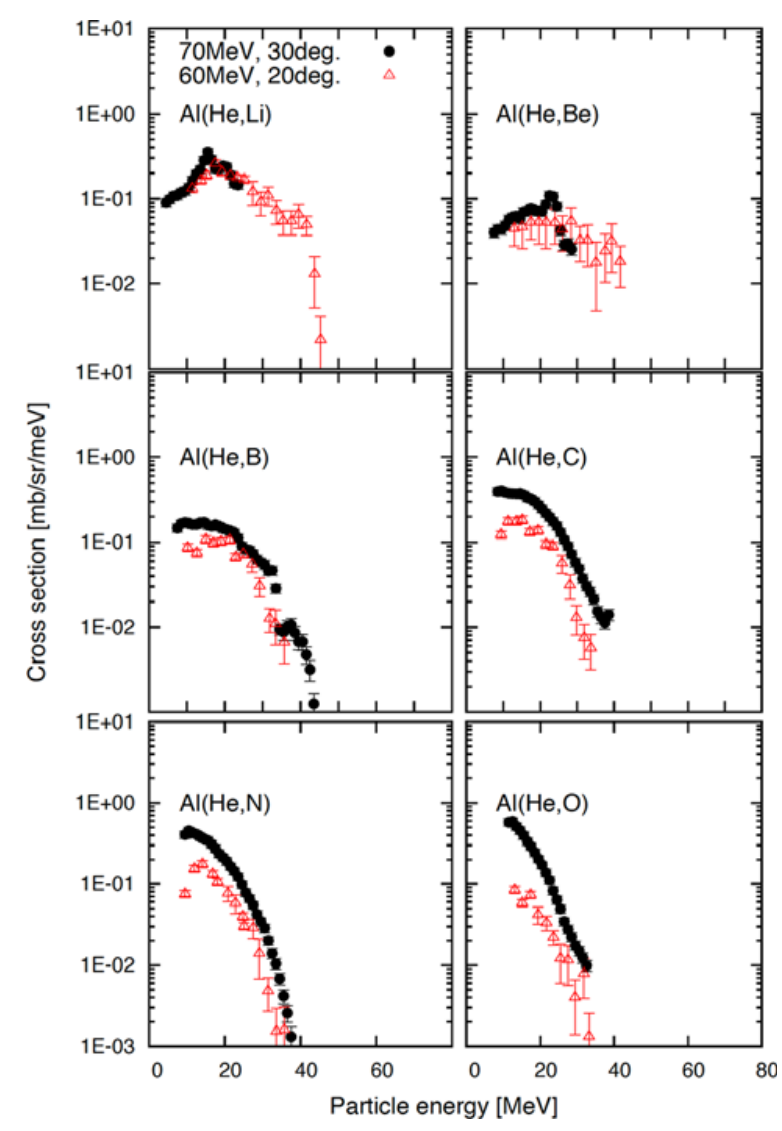

Figure 5. Double differential cross sections of the $\mathrm{Al}(\mathrm{He}, \mathrm{x})$ reaction for $\mathrm{E}_{\mathrm{He}}=70 \mathrm{MeV}$, at 30 degrees emission angle in comparison with ones for $\mathrm{E}_{\mathrm{He}}=60 \mathrm{MeV}$, at 20 degrees by Bhattacharya et al. [10].

were converted to energy spectra using energy calibration data. The calibration data were determined based on maximum deposition energies for each fragment that were calculated using the SRIM code [1] for operated counting gas pressure. The energy spectra were shifted to compensate for energy losses in the target and entrance window. The half of target thickness was used for compensation of energy loss in the target.

After energy compensation, the energy spectra, $Y(E, \theta)$ were normalized according to the following equation:

$$
\frac{d^{2} \sigma}{d E d \Omega}(E, \theta)=\frac{Y(E, \theta)}{\phi N \Delta E \Delta \Omega},
$$

where $\varphi$ is the number of protons that were obtained using Faraday cup, $N$ the number of the target atoms, $\Delta E$ bin width, $\Delta \Omega$ solid angle deduced analytically and confirmed through $\alpha$-particle counting from ${ }^{241} \mathrm{Am}$ check source placed instead of target.

Uncertainties of statistics and others, the number of incident particles $(5 \%)$, the number of target atoms $(6 \%)$, solid angle (6\%), were included within the data based on propagation of uncertainty.

\section{Results and discussion}

Figure 5 shows double differential cross sections of the $\mathrm{Al}(\mathrm{He}, \mathrm{x})$ reaction for $\mathrm{E}_{\mathrm{He}}=70 \mathrm{MeV}$, at 30 degrees emission angle in comparison with one for $\mathrm{E}_{\mathrm{He}}=60 \mathrm{MeV}$, 


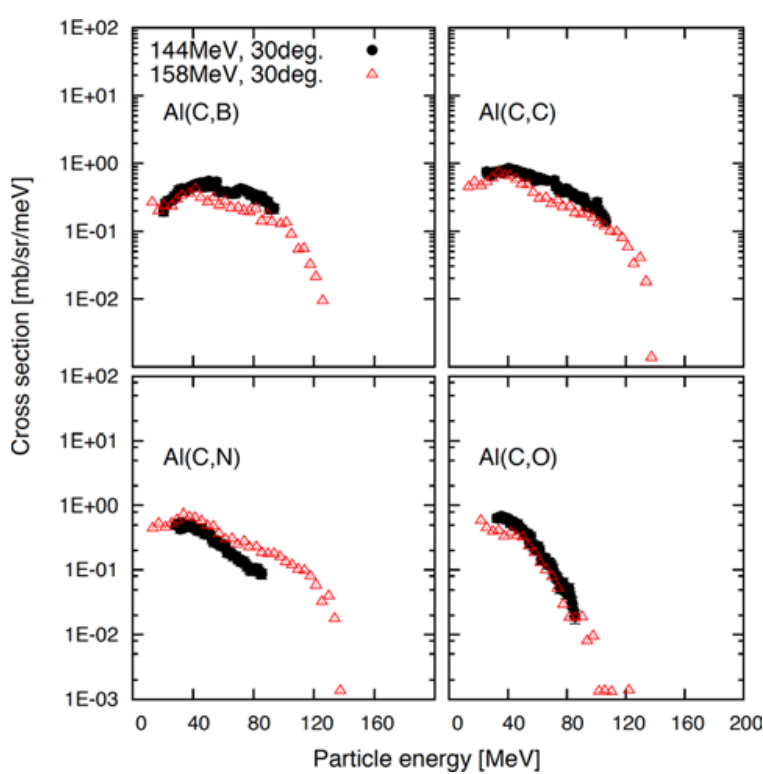

Figure 6. Double differential cross sections of the $\mathrm{Al}(\mathrm{C}, \mathrm{x})$ reaction for $\mathrm{E}_{\mathrm{C}}=144 \mathrm{MeV}$, at 30 degrees emission angle in comparison with one for $\mathrm{E}_{\mathrm{He}}=158 \mathrm{MeV}$, at 30 degrees by S.V.Fortsch et al. [11].

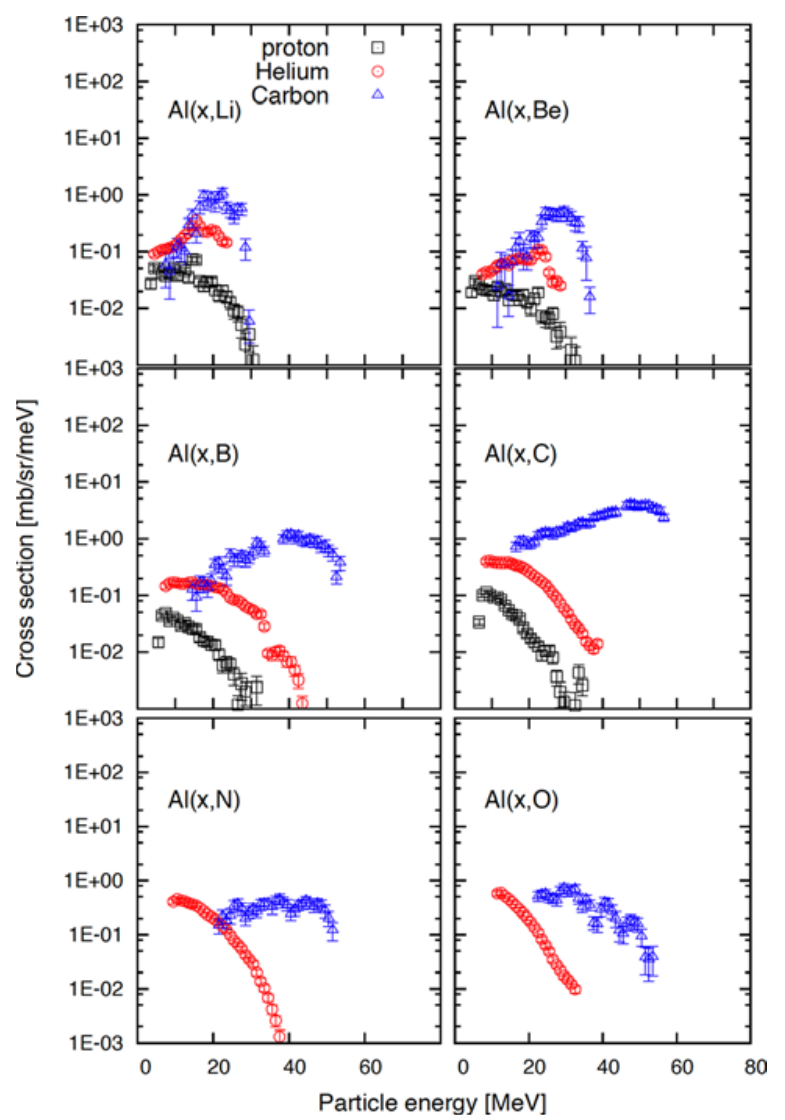

Figure 7. Double differential cross sections of aluminium target for $\mathrm{Li}, \mathrm{Be}, \mathrm{B}, \mathrm{C}, \mathrm{N}$ and $\mathrm{O}$ production at 30 degrees emission angle for $70 \mathrm{MeV}$ proton, helium and carbon.

at 20 degrees by Bhattacharya et al. [10]. As shown in this figure, present results for $70 \mathrm{MeV}$ at 30 degrees are in fair agreement with data for $60 \mathrm{MeV}$, at 20 degrees with considering difference of incident energy and emission angle. Present data miss high energy components of light

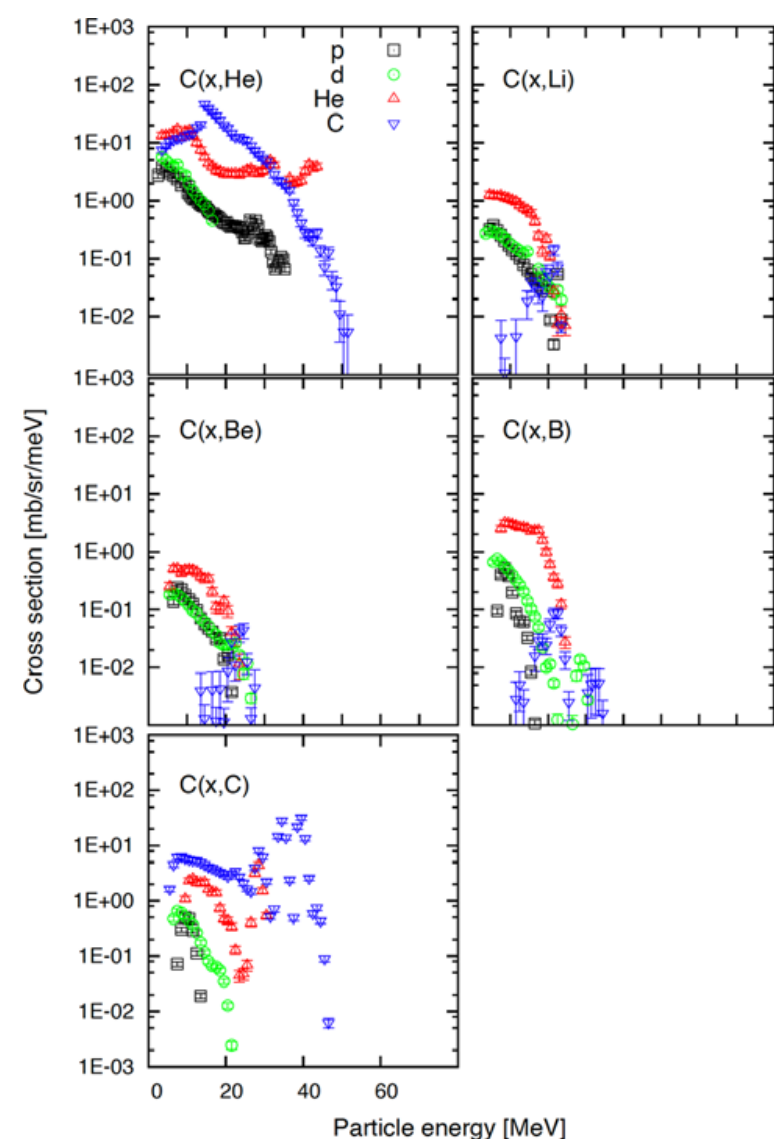

Figure 8. Double differential cross sections of carbon target for $\mathrm{Li}, \mathrm{Be}, \mathrm{B}, \mathrm{C}, \mathrm{N}$ and $\mathrm{O}$ production at 30 degrees emission angle for $50 \mathrm{MeV}$ proton, helium and carbon incident.

mass fragments, $\mathrm{Li}$ and $\mathrm{Be}$, due to insufficient detector thickness, however the data covers energy range for relatively higher yield.

Figure 6 shows double differential cross sections of the $\mathrm{Al}(\mathrm{C}, \mathrm{x})$ reaction for $\mathrm{E}_{C}=144 \mathrm{MeV}$, at 30 degrees emission angle in comparison with one for $\mathrm{E}_{H e}=$ $158 \mathrm{MeV}$, at 30 degrees by S.V.Fortsch et al. [11]. Present data for $144 \mathrm{MeV}$ seems to be consistent with data for $158 \mathrm{MeV}$.

Figure 7 shows double differential cross sections of aluminium for $\mathrm{Li}, \mathrm{Be}, \mathrm{B}, \mathrm{C}, \mathrm{N}$ and $\mathrm{O}$ production at 30 degrees emission angle for $70 \mathrm{MeV}$ proton, helium and carbon incident. Generally, amount of fragment emitted from these reaction increases with mass of projectiles. Naturally, carbon emission is high for carbon-induced reaction since it includes simple scattering components. In addition to this, emission of $\mathrm{B}$ and $\mathrm{N}$, which are neighbour of carbon, are relatively high. It indicates, scattering and pickup/stripping component provide considerable contribution for light mass fragment production in this energy range.

Figure 8 shows double differential cross sections of carbon target for $\mathrm{Li}, \mathrm{Be}, \mathrm{B}, \mathrm{C}, \mathrm{N}$ and $\mathrm{O}$ production at 30 degrees emission angle for $50 \mathrm{MeV}$ proton, deuteron helium and carbon incident. As shown in this figure, relatively high carbon emission for carbon induced reaction is observed for the $\mathrm{C}(\mathrm{C}, \mathrm{C})$ reaction. Some peak structures due to low-lying state of residual nuclei are observed for carbon emission in addition to continuous energy component. For Boron, yield is comparable to 


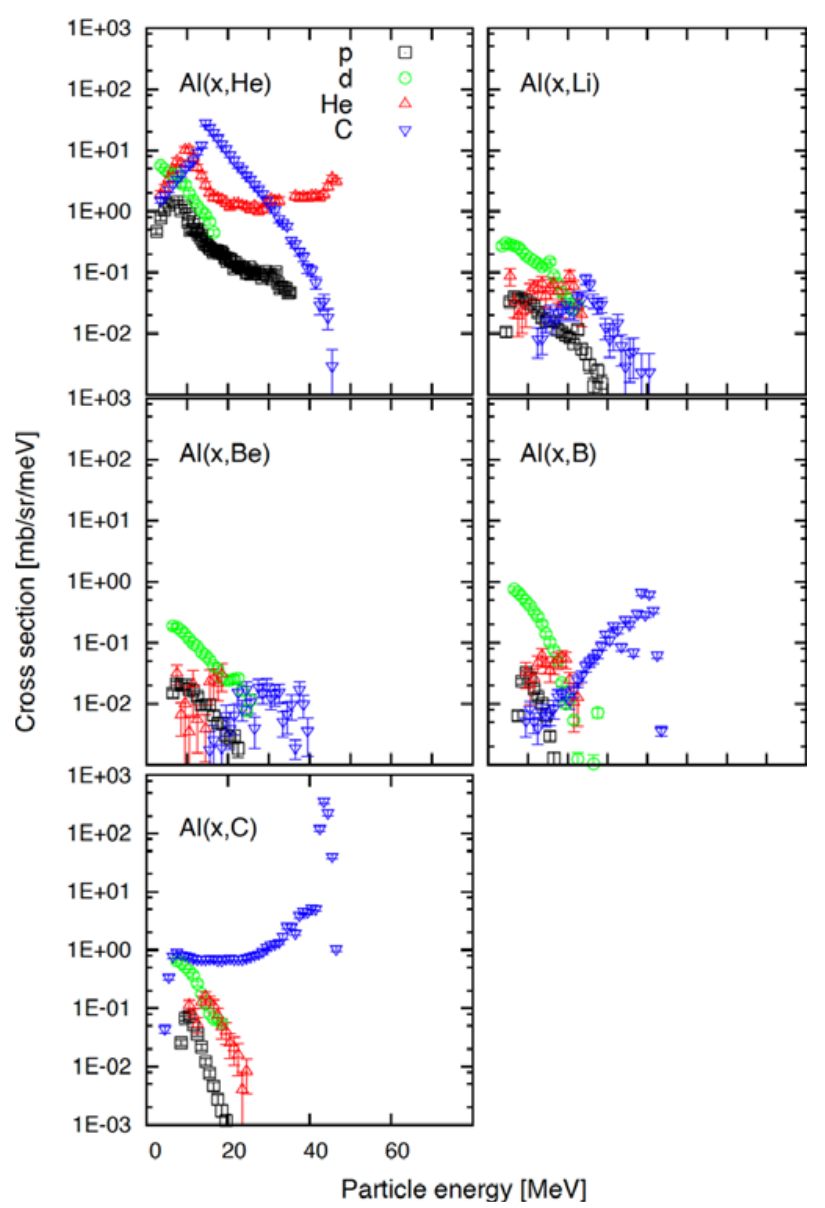

Figure 9. Double differential cross sections of aluminium target for $\mathrm{Li}, \mathrm{Be}, \mathrm{B}, \mathrm{C}, \mathrm{N}$ and $\mathrm{O}$ production at 30 degrees emission angle for $50 \mathrm{MeV}$ proton, helium and carbon.

one for $\mathrm{Be}$ and $\mathrm{Li}$. It indicates stripping process is not important in this case.

In contrast, helium particle emission for carboninduced reaction is significantly higher than the other particles. It indicates importance of carbon decay to three helium particles. For the $\mathrm{C}(\mathrm{He}, \mathrm{He})$ reaction, relatively large amount of high energy components are observed due to scattering of helium.

Figure 9 shows double differential cross sections of aluminium for $\mathrm{Li}, \mathrm{Be}, \mathrm{B}, \mathrm{C}, \mathrm{N}$ and $\mathrm{O}$ production at 30 degrees emission angle for $50 \mathrm{MeV}$ proton, deuteron helium and carbon incident. For the $\mathrm{Al}(\mathrm{C}, \mathrm{C})$ reaction, peak structure is observed due to elastic and inelastic scattering. The yield for Boron is relatively high in comparison with one for $\mathrm{Li}$ and $\mathrm{Be}$ in contrast to the reaction on carbon, which means stripping process is more important for aluminium than carbon.

For helium emission, same tendencies shown in Fig. 8 are observed in Fig. 9. For quantitative comparison between carbon and aluminium, energy integrated cross sections were deduced for these spectrum. In this integration, missing components due to low energy threshold of detector system were neglected.

Figure 10 shows energy integrated cross sections of each projectile for carbon and aluminum targets with $50 \mathrm{MeV}$ incident energy, 30 degrees emission angle, as a function of ejectile Z-number. The figure clearly shows above mentioned tendencies, i.e., increase of carbon
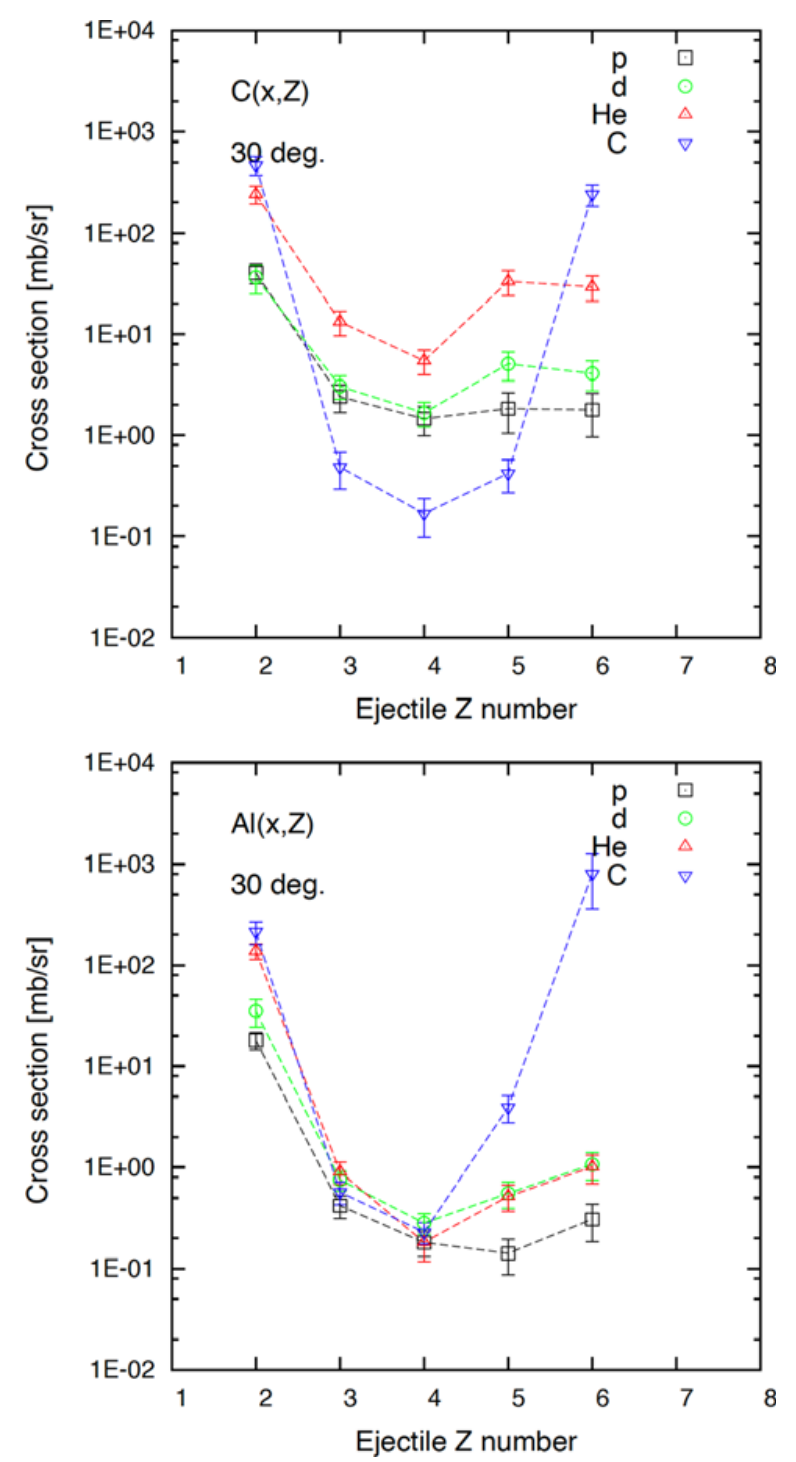

Figure 10. Energy integrated cross sections of each projectile and ejectile for carbon and aluminum targets with $50 \mathrm{MeV}$ incident energy, 30 degrees emission angle. Dotted lines connecting data points are eye guide.

emission for carbon incident reaction, difference of boron emission for carbon and aluminum targets.

\section{Conclusions}

The sets of experimental data were obtained for fragment production with combinations of projectile and target nucleus for four different incident particles, p, d, He and $\mathrm{C}$, having same energy, on light to medium nuclei targets. Light mass fragments of $\mathrm{Li}, \mathrm{Be}, \mathrm{B}, \mathrm{C}, \mathrm{N}$ and $\mathrm{O}$ were measured at 30, 60 and 90 degrees using Bragg curve counter with scattering chamber. From these results, importance of scattering, stripping and picking-up processes becomes obvious to reproduce light mass fragment production in this energy range. Contribution of break up reaction on carbon providing three helium particles was also observed from this spectrum. The data set must be useful for validation of reaction models implemented in radiation transport codes. 
The authors would like to thank the staff and operators of Cyclotron facility, National Institute of Radiological Science in Japan. This work is partially supported by JSPS Grants-in-Aid for Scientific Research (C) (KAKENHI) Grant Number 24561051.

\section{References}

[1] J.F. Ziegler et al., The Stopping and Range of Ions in Solids, Pergamon (New York, 1985)

[2] T. Sato et al., J. Nucl. Sci. Technol. 50(9), 913-923 (2013)

[3] A. Bubak et al., Physical Review C76, 014618 (2007)

[4] H. Machner et al., Physical Review C73, 044606 (2006)
[5] R.E.L. Green et al., Physical Review 22,1594 (1980)

[6] T. Sanami et al., Nuclear Instruments and Methods A589, 193 (2008)

[7] M. Hagiwara et al., Nuclear Instruments and Methods A592, 73 (2008)

[8] T. Sanami et al., Journal of Korean Physics Society 59, 1805 (2011)

[9] M. Hagiwara et al., Journal of Nuclear Science and Technology 49(6), 571 (2012)

[10] C. Bhattacharya et al., Physical Review C44, 1049 (1991)

[11] S.V. Förtsch et al., Nuclear Physics A797, 1 (2007)

[12] T. Motobayashi et al., Nuclear Physics A331, 193 (1979) 